\title{
O papel da Olimpíada Escolar na formação de atletas brasileiros
}

http://dx.doi.org/10.11606/1807-5509201800030475

\author{
André Almeida Cunha ARANTES* \\ Francisco MARTINS** \\ Pedro SARMENTO*** \\ Gislane Ferreira de MELO****
}

*Departamento de Educação Física, Centro Universitário de Brasilia, Brasilia, DF, Brasil. ${ }^{* *}$ Universidade Federal da Paraíba, Joao Pessoa, PB, Brasil.

${ }^{* * *}$ Faculdade

de Desporto Universidade do Porto, Porto, Portugal. ****Universidade Católica de Brasilia, Brasilia, DF, Brasil.

\section{Resumo}

0 objetivo deste estudo foi analisar o papel da Olimpiada Escolar (OE) no processo de descoberta e desenvolvimento de talentos esportivos no cenário esportivo nacional. A amostra foi constituída pelos atletas escolares medalhistas do sexo masculino e feminino, em seis modalidades, faixa etária de 12 a 14 anos entre os anos 2005 e 2010. Criaram-se critérios de seleção que possibilitaram a aferição do nível técnico da amostra. Confrontando a amostra com os critérios propostos, chegou-se à identificação de 46,3\% talentos esportivos no período estudado. A pesquisa identificou que de 2005 a 2010 existiu um aumento significativo de 53,7\% na taxa de identificação dos talentos esportivos. Em relação ao percentual de identificação por sexo, o feminino foi maior do que o masculino. Em função da crescente identificação de talentos, pode-se concluir que a Olimpiada Escolar tem cumprido papel relevante no processo de descoberta e desenvolvimento de talentos esportivos no Brasil.

Palavras-chave: Competições escolares; Esporte escolar; Talentos esportivos.

\section{Introdução}

A busca da identificação de fatores relativos ao ambiente esportivo que concorrem para a formação e promoção de talentos esportivos é temática recente na literatura nacional e internacional. Estudiosos de diferentes países têm desenvolvido pesquisas que buscam verificar semelhanças na estrutura de desenvolvimento esportivo em países que se destacam em termos de resultados no âmbito mundial ${ }^{1-2}$.

Uma das primeiras abordagens sobre o tema na literatura internacional é apresentada por GREeN e OAKLEY ${ }^{1}$, que analisaram a importância que a identificaçáo e o monitoramento dos talentos tiveram para os países do Leste Europeu, com destaque para a antiga União Soviética e Alemanha Oriental. Os autores ressaltam que esses processos continuam relevantes para a consolidação de um sistema de esporte de elite em países como Reino Unido, França, Espanha, Canadá, Estados Unidos e Austrália.

O trabalho desenvolvido por DigeL ${ }^{3}$, considerado um marco para o estudo do tema, objetivou elaborar um modelo de análise das estruturas que contribuem para o sucesso do esporte de alto rendimento. Ao analisar oito países (Austrália, China, Alemanha, França, Reino Unido, Itália, Rússia e Estados Unidos), o autor aponta, entre outros fatores, o papel do sistema educacional no desenvolvimento do esporte de alto rendimento, formado pela escola e a universidade, em alguns países, e por escolas de formação em modalidades esportivas e/ou clubes esportivos, em outros, destacando ainda o oferecimento de competiçóes escolares.

Mais recentemente, um novo modelo teórico e de análise comparativa de sistemas esportivos 
foi proposto por De Bosscher et al. ${ }^{2}$, a partir de nove pilares. São eles: suporte financeiro; organização e estrutura política esportiva; participação; identificação de talentos; apoio para atletas; infraestrutura de treinamento; provimento e desenvolvimento de treinadores; competições; e pesquisa cientifica. O pilar participação está baseado nodesenvolvimento do esporte na escola através da disciplina de Educação Física, do esporte extracurricular e de um sistema de competição próprio; e o pilar identificação de talentos, por um sistema de descoberta e monitoramento de talentos.

Fica então evidenciado que a estrutura do esporte e programas voltados a dar suporte ao desenvolvimento de atletas é tema relevante para a compreensão do processo de desenvolvimento esportivo de um país ${ }^{4}$. No Brasil, esta preocupaçáo se manifesta em termos de açóes e políticas de Estado historicamente adotadas em apoio ao desenvolvimento do esporte. Nesta pesquisa destacam-se as voltadas ao esporte escolar e de forma mais especifica a competiçáo escolar.

No final da década de 1960, com o objetivo de favorecer a integração nacional e descobrir talentos esportivos, o Departamento de Educação Física e Desporto do Ministério da Educação e Cultura (DED/MEC) implantou uma competição escolar de âmbito nacional denominada Jogos Estudantis Brasileiros (JEB's). Desde então, ao longo dos anos, os Jogos ocorreram anualmente, com uma única interrupção em 1999, embora sua denominação tenha sido recorrentemente alterada ${ }^{5}$.

A Olimpíada Escolar (OE), nomenclatura usada para designar os Jogos no período estudado, de 2005 a 2010 , teve adesão crescente de atletas escolares. No ano de 2005 foram 2327 e em 2010 já somavam 3.068, sendo que todas as ediçôes contemplaram as faixas etárias de 12 a 14 anos e de 15 a 17 anos, e o número de modalidades esportivas cresceu de 8 para $11^{5}$.

Estes dados são importantes para a compreensão das $\mathrm{OE}$, porém, não informam sobre a qualidade técnica destes Jogos. Portanto, este artigo, teve como objetivo verificar o papel da Olimpíada Escolar no processo de descoberta e desenvolvimento de talentos esportivos no cenário esportivo nacional, por meio da apuração da qualidade técnica das $\mathrm{OE}$, uma vez que a qualidade técnica tem ligação direta com a relevância da contribuição destes Jogos. Trata-se de responder à seguinte questão: os atletas escolares que participaram na $\mathrm{OE}$ situam-se entre os mais destacados atletas brasileiros em suas modalidades, sexo e faixa etária?

\section{Método}

\section{Natureza do Estudo}

Caracterizou-se como pesquisa documental, com a busca de informaçóes nos boletins oficiais das OE, e descritiva ao apresentar os resultados dos melhores atletas escolares na faixa etária de 12 a 14 anos entre 2005 e 2010 e compará-los aos resultados dos melhores atletas federados no cenário esportivo nacional.

\section{Amostra}

Inicialmente, foram definidos 800 atletas escolares entre 12 e 14 anos de um total de 15.720 participantes nas ediçóes da OE de 2005 a 2010. O levantamento de dados referente aos 800 atletas escolares foi feito junto aos relatórios técnicos realizados pelo Comitê Olímpico Brasileiro entre 2005 e 2010, considerando os três melhores atletas escolares $\left(1^{\circ}, 2^{\circ}\right.$ e $3^{\circ}$ lugares) nas modalidades natação, xadrez e tênis de mesa; os três melhores times de basquete e handebol e os quatro melhores resultados de judô. Deste total $49,9 \%$ foram atletas escolares do sexo feminino e $50,1 \%$ do sexo masculino.

Cabe ressaltar que a escolha da faixa etária de 12 a 14 anos foi realizada por ser uma faixa etária mais próxima do início da etapa de especialização em diferentes modalidades ${ }^{4}$, e porque bons resultados nas competiçóes estáo entre os fatores iniciais que consolidam o atleta na fase da especialização ${ }^{6}$.

\section{Instrumento e procedimento}

Para a definição dos "talentos esportivos" utilizou-se o critério (protocolo) recomendado por CAFruni et al. ${ }^{7}$. Assim, foram consultados formalmente, os Coordenadores de modalidades da OE e técnicos das Confederaçóes Esportivas Brasileiras no sentido de se determinar os "melhores critérios de seleção" para cada modalidade (QUADRO 1). 
QUADRO 1 - Critério de seleção por modalidade esportiva.

\begin{tabular}{|l|c|c|}
\hline Modalidades & Critério de seleção & Evento \\
\hline Natação & Até a $8^{a}$ colocação & Ranking Brasileiro \\
\hline Basquetebol & Presença na Seleção Estadual & Campeonato Brasileiro \\
\hline Handebol & Presença na Seleção Estadual & Campeonato Brasileiro \\
\hline Judô & Até a 5 colocação & Campeonato Brasileiro \\
\hline Xadrez & Até a $10^{a}$ colocação & Campeonato Brasileiro \\
\hline \multirow{2}{*}{ Tênis de Mesa } & Até a 5a colocação & Campeonato Norte e Nordeste \\
\cline { 2 - 3 } & Até a 8 $8^{\text {a colocação }}$ & $\begin{array}{c}\text { Campeonato Sul e Sudeste } \\
\text { Obs.: não existe Campeonato Brasileiro. }\end{array}$ \\
\hline
\end{tabular}

A dificuldade inicial no processo de determinação dos "critérios de seleção" residiu no fato de que as modalidades são diferentes e com nível de competitividade muito distinto. Estabelecer critério que pudesse, ao mesmo tempo, ser objetivo e que também levassem em consideração estas diferenças foi o grande desafio. Nesse sentido, a busca pela experiência técnica dos Coordenadores de modalidades da OE e dos técnicos das Confederações esportivas foi o que possibilitou estabelecer "critérios de seleção" específicos para cada uma das modalidades que no final traduzissem uma mensagem semelhante, ou seja, aqueles que poderiam ser considerados os melhores atletas do país na faixa etária 12 a 14 anos.

\section{Análise de Dados}

Para as análises descritivas dos dados foram utilizados médias, desvios padróes e frequências. Já para análises inferenciais foram realizados testes Qui-Quadrado para estabelecer comparaçáo entre as frequências anuais e por sexo (dados qualitativos). O software SPSS-IBM 22.0 for Windows foi escolhido para realizar as análises e o nível de significância estipulado foi de $\mathrm{p} \leq 0,05$.

\section{Resultados}

Em função dos critérios adotados, da amostra inicial de 800 atletas escolares selecionou-se 370 talentos esportivos, distribuídos conforme demonstra a TABELA 1.

Conforme a TABELA2, comparando-se número de talentos esportivos identificados em 2005 e o número encontrado em 2010, constata-se crescimento de 53,7\% no número de talentos identificados neste período.

Em termos de representação por sexo, verificouse que a representação feminina foi maior que a masculina no que tange à qualidade dos resultados esportivos nesta pesquisa. A diferença no percentual de identificação entre os sexos, no período estudado, foi de $16,8 \%$ favorável ao sexo feminino, como pode ser observado na FIGURA 1.

Entre 2005 e 2010, a representação feminina teve um percentual de identificação superior à masculina, apesar de não significativa como demonstra a FIGURA 2. Entretanto, se compararmos a primeira edição, em 2005, com a última, em 2010, é possível perceber que existe um movimento ascendente na identificação da representação masculina de talentos $(\mathrm{p}=0,002)$

TABELA 1 - Número e percentual de talentos esportivos.

\begin{tabular}{lccc}
\hline Modalidades & $\begin{array}{c}\text { Atletas escolares participantes das Olimpíadas } \\
\text { escolares entre } \mathbf{2 0 0 5} \mathbf{- 2 0 1 0}\end{array}$ & $\begin{array}{c}\text { Talentos esportivos } \\
\text { \% por modalidade }\end{array}$ \\
\hline Tênis de Mesa & 30 & 23 & 76,67 \\
Handebol & 8 & 6 & 75,00 \\
Basquetebol & 30 & 15 & 50,00 \\
Judô & 384 & 174 & 45,31 \\
\hline
\end{tabular}


Ganzer VR, et al.

Continuação

TABELA 1 - Número e percentual de talentos esportivos.

\begin{tabular}{lccc}
\hline Modalidades & $\begin{array}{c}\text { Atletas escolares participantes das Olimpíadas } \\
\text { escolares entre } \mathbf{2 0 0 5}-\mathbf{2 0 1 0}\end{array}$ & $\begin{array}{c}\text { Talentos esportivos } \\
\text { \% por modalidade }\end{array}$ & $\begin{array}{l}\text { \% podán } \\
\text { Nataçá }\end{array}$ \\
Xadrez & 312 & 141 & 45,19 \\
Total Geral & $\mathbf{8 0 0}$ & 11 & 30,56 \\
\hline
\end{tabular}

TABELA 2 - Número talentos esportivos identificados por ano.

$p=0,03$

\begin{tabular}{lcccccc}
\hline Ano & $\mathbf{2 0 0 5}$ & $\mathbf{2 0 0 6}$ & $\mathbf{2 0 0 7}$ & $\mathbf{2 0 0 8}$ & $\mathbf{2 0 0 9}$ & $\mathbf{2 0 1 0}$ \\
\hline Modalidades & & & & & & \\
\hline Tênis de Mesa & 0 & 3 & 6 & 5 & 5 & 4 \\
Xadrez & 0 & 1 & 2 & 5 & 1 & 2 \\
Judô & 41 & 22 & 21 & 29 & 29 & 32 \\
Handebol & 0 & 1 & 0 & 4 & 1 & 0 \\
Basquetebol & 2 & 1 & 0 & 5 & 3 & 4 \\
Natação & 11 & 17 & 10 & 31 & 31 & 41 \\
Total & $\mathbf{5 4}$ & $\mathbf{4 5}$ & $\mathbf{3 9}$ & $\mathbf{7 9}$ & $\mathbf{7 0}$ & $\mathbf{8 3}$ \\
\hline
\end{tabular}

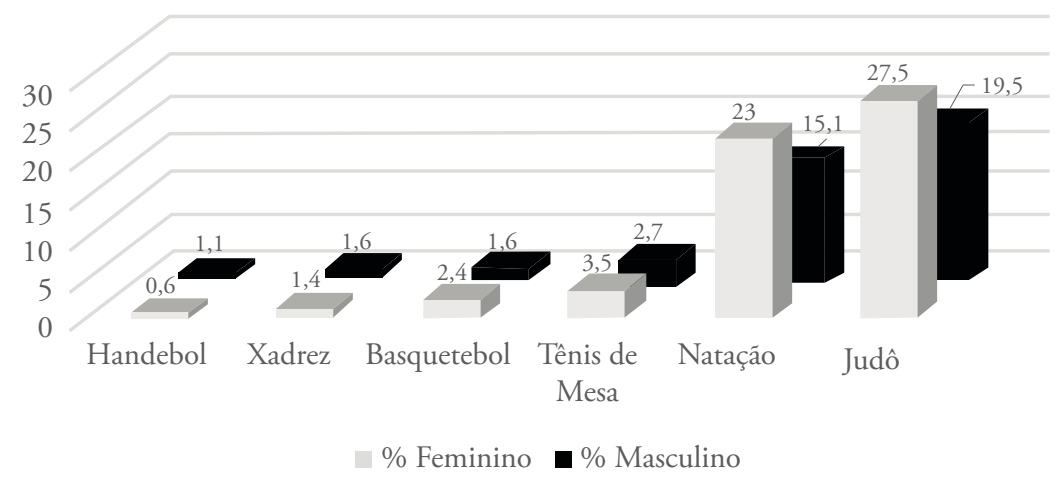

FIGURA 1: Percentual de talentos esportivos identificados por sexo.

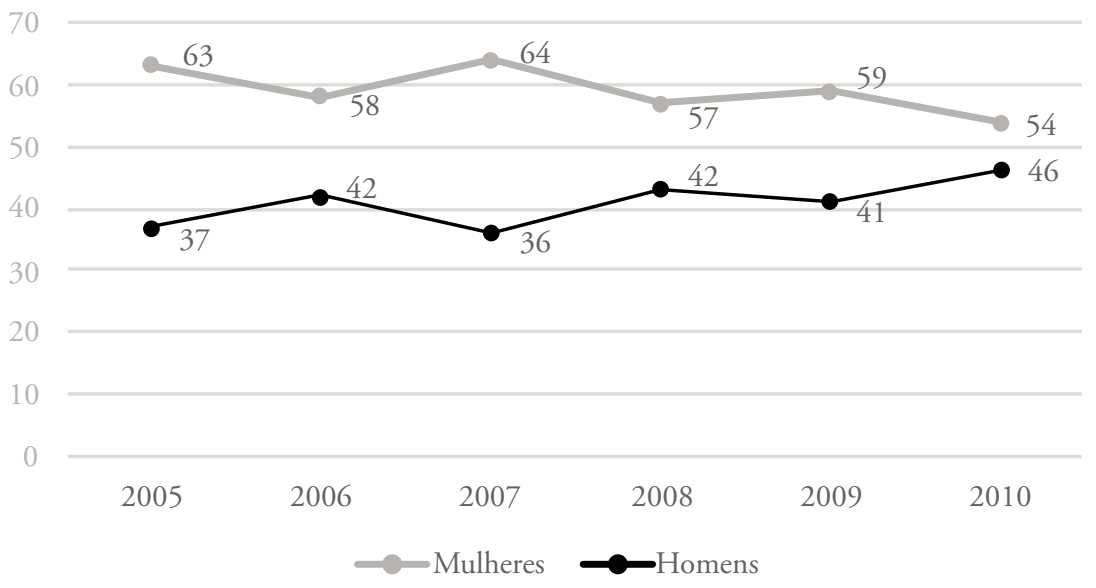

FIGURA 2 - Percentual de talentos esportivos identificados por sexo e ano. 


\section{Discussão}

O objetivo deste estudo foi verificar o papel da Olimpíada Escolar no processo de descoberta e desenvolvimento de talentos esportivos no cenário esportivo nacional, e também responder se os atletas escolares que participaram na $\mathrm{OE}$ situavam-se entre os mais destacados atletas brasileiros em suas modalidades, sexo e faixa etária.

Os resultados demonstram que o percentual de talentos esportivos identificados no período estudado (2005-2010), segundo os critérios de seleção sugeridos pelos Coordenadores de modalidades da OE e dos técnicos das Confederaçóes Esportivas foi de 46,30\%, um número bem representativo. Observa-se, também, um incremento de $53,7 \%$ de atletas definidos como talentos entre os anos de 2005 e 2010, o que demonstra um aumento significativo na identificação de talentos esportivos ao longo dos anos.

As mulheres apresentaram valores mais altos quanto à qualidade da representação esportiva. Levados pela importância atribuída a representação feminina no esporte por Mathias et $\mathrm{al}^{8}$, este resultado intrigou os pesquisadores: por que as mulheres apresentaram um nível técnico mais elevado nas Olimpíadas Escolares?

Os Parâmetros Curriculares Nacionais (PCN) ${ }^{9}$ apresentam como objetivos gerais do ensino fundamental a não "discriminação por características sexuais". As escolas e particularmente os professores de Educação Física tem estimulado a participação feminina nas aulas de Educação Física, nos esportes e em competiçóes. Silva, Dantas, Medeiros e Bahia ${ }^{10}$ apresentam resultado de pesquisa em que se nota o aumento da participaçáo feminina nos Jogos Estudantis da Rede Pública da Bahia entre os anos de 2008 e 2012. A participaçáo de talentos esportivos do sexo feminino nos Jogos provavelmente sofreu influência do ambiente estimulador presente no meio educacional.

Por outro lado, acredita-se que as mulheres percebem a importância que este evento tem, pois abre caminhos para o recebimento de vários benefícios como, por exemplo, bolsa atleta ou bolsa na escola ${ }^{11}$.

Quanto à participação por modalidades observase que a nataçáo e o judô foram os esportes com maior representação e nem por isso foram os esportes com maiores valores de talentos encontrados. As duas modalidades são tradicionais, com resultados importantes a nível internacional e tem calendário esportivo bem intenso para categorias de base. É possível que esta grande oferta de competiçóes concorra com as OE's e dificulte a participaçáo de alguns bons atletas na competição escolar.
Os valores alcançados ano a ano tornaram viável o monitoramento da qualidade do nível técnico da Olimpíada Escolar, possibilitando, assim, a mensuração dos resultados e sua comparação anual. Por meio desses valores, foi possível verificar um importante percentual de atletas escolares que estão situados entre os mais destacados atletas brasileiros em suas modalidades, sexo e faixa etária.

A preocupação em mensurar o nível técnico dos Jogos Escolares Brasileiros não é nova. Na década de 1970, a implantação do plano nacional de Educação Física e Desporto - PNED levou o Departamento de Desportos e Educação Física a criar a Comissão de Avaliação, que tinha como objetivo avaliar a situação do Esporte Escolar no Brasil e sugerir medidas que possibilitassem a evolução do mesmo, buscando, dessa forma, elevar o nível técnico dos JEB's' ${ }^{12}$.

Depois de três anos de pesquisas, elaborou-se o manual utilizado na Avaliação do X Jogos Escolares Brasileiros de $1979^{13}$, que trouxe como um dos objetivos "possibilitar o levantamento de dados, determinando o padrão das provas, das equipes, dos desportos e dos atletas, classificando-os em categorias, visando à melhoria do nível técnico". A definição de categorias tentava classificar os resultados segundo critérios de maior ou menor desenvolvimento técnico. O processo foi complexo e chegou a seguinte sugestão: Categoria C-Alto Nível; Categoria B - Competitiva; Categoria A - Iniciação e Categoria M - Massa. De uma forma geral, nos registros apreciados, a indicação é que as modalidades e os atletas se localizavam na categoria "Massa", alguns categorizados como "Iniciação" e poucos na categoria "Competitiva".

A dificuldade de comparar os dados da Comissão de Avaliação do MEC $^{13-16}$ com os da presente pesquisa residem no fato das metodologias serem muito diferentes. A tentativa de estabelecer indicadores para mensurar o nível técnico dos Jogos pelo MEC faz uma análise de todos os participantes, enquanto a presente metodologia se restringe a estudar os melhores de cada modalidade.

Buscou-se, entâo, comparar os achados desta pesquisa com informaçōes relativas à participação da delegação brasileira na primeira edição dos Jogos Olímpicos da Juventude (YOG), que ocorreram em Cingapura no ano de 2010. Esse evento foi organizado pelo Comitê Olímpico Internacional (COI) para atletas com menos de 18 anos de idade.

É fato que as idades da delegação brasileira que participaram do YOG (até 18 anos) são diferentes 
das idades deste estudo sobre a Olimpíada Escolar (12 a 14 anos), e que isso implica uma limitação. Contudo, é válida a comparação devido à escassez de dados disponíveis para esse fim.

A delegação brasileira no YOG foi composta por oitenta atletas escolares que participaram em uma ou nas duas faixas das Olimpíadas Escolares, 12 a 14 anos e 15 a 17 anos, entre 2005 e 2009, segundo o Comitê Olímpico Brasileiro - $\mathrm{COB}^{17}$. Levando-se em consideração apenas as vagas relativas às modalidades coincidentes com as da $\mathrm{OE}$, chega-se a cinquenta e nove vagas. Destas, trinta e seis foram preenchidas por atletas escolares oriundos da $\mathrm{OE}$ segundo o $\mathrm{COB}^{17}$, portanto $61 \%$.

Embora não tenha sido possível o cálculo do percentual de identificaçáo do atletismo na presente pesquisa, essa modalidade teve participação significativa de atletas escolares na delegação brasileira do YOG.

Em relação ao sexo, na delegação que foi ao YOG encontrou-se a presença de 20 atletas escolares do sexo feminino e 16 atletas escolares do sexo masculino ${ }^{17}$. Ou seja, os achados da atual pesquisa em relação ao sexo verificam-se na composição da delegação brasileira presentes no YOG.

Em recente informação fornecida pelo $\mathrm{COB}^{18}$ a delegação brasileira que esteve na Olimpíada RIO 2016, contou com a presença de 52 atletas que participaram das $\mathrm{OE}$ entre os anos 2005 e 2013. Deste total, $42 \%$ de homens e $58 \%$ de mulheres, portanto também corroborando com os dados da pesquisa que mostram uma representação feminina de melhor qualidade técnica nas OE.

As informaçôes encontradas na presente pesquisa e a composição das delegaçóes brasileiras no YOG 2010 e RIO 2016, reforçam a importância das OE na descoberta e formação de talentos esportivos e sua contribuição diferenciada ao sexo feminino. Dessa forma, e com base nesses dados, pode-se concluir que a Olimpíada Escolar tem cumprido papel relevante no processo de descoberta e desenvolvimento de talentos esportivos no país.

A contribuição prática desta pesquisa está nas informaçóes que comprovam a importância das OE para a descoberta e desenvolvimento de talentos esportivos e a contribuição teórica está na apresentação de ferramenta para o monitoramento do nível técnico dos Jogos com base em critérios de seleção que foram criados a partir da experiência de Coordenadores de modalidades da OE e dos técnicos das Confederaçôes esportivas. Sugerese que novos estudos sejam desenvolvidos no sentido de monitorar a participação e desempenho de atletas escolares de 15 a 17 anos, buscando verificar o comportamento do nível técnico também nesta faixa etária.

\section{Abstract}

The role of the Brazilian School Games in development of Brazilian athletes

This study aims to analyze the role of the Brazilian School Games (BSG) in the process of discovery and development of sports talent in the national sports scene. The sample was constituted by the school athletes medalists female and male, in six sports, aged 12 to 14 years between 2005 and 2010. Selection criteria were created to evaluate the technical level of the sample. Confronting the sample with the proposed criteria, we reached the identification of $46.3 \%$ talented during the study period. The research identified that 20052010 there was a significant increase of 53.7\% in the identification rate of the talented. Regarding gender identification, the percentage of identification for females was found to be larger than in the male sample. Due to the growing talent identification it can be concluded that the BSG has fulfilled an important role in the process of discovery and development of sports talent in the Brazil.

KEYWORDS: School competitions; School sports; Sports talent.

\section{Referências}

1. Green M, Oakley B. Elite sport development systems and playing to win: uniformity and diversity in international approaches. Leis. Stud. 2001;20:247-76. 
2. De Bosscher V, De Knop P, Bottenburg M, Shibli S, Bingham J. Explaining international sporting success: an international comparison of elite sport systems and polices in six countries. Sport Management Review. 2009;12:13-136.

3. Digel H. A comparison of competitive sport systems. New Studies in Athletics. 2002;17(1):37-50.

4. Böhme MTS, organizadora. Esporte infantojuvenil: treinamento em longo prazo e talento esportivo. São Paulo: Phorte; 2011.

5. Arantes ACA, Martins FS, Sarmento JP. Jogos Escolares Brasileiros: reconstrução histórica. Motriz. 2012;8(supl 2):916-24.

6. Peres L, Lovisolo H. Formação esportiva: teoria e visões do atleta de elite no Brasil. Rev. educ. fis. 2006;17(2):211-18.

7. Cafruni C, Marques A, Gaya A. A análise da carreira desportiva de atletas das regióes sul e sudeste do Brasil: estudos dos resultados desportivos nas etapas de formação. Revista Portuguesa de Ciências do Desporto. 2006;6(1):55-64.

8. Mathias MB, Leite CM, Rubio K. Gênero e participação olímpica: educação olímpica e responsabilidade social. In: Rubio K. Educação olímpica e responsabilidade social. São Paulo: Casa do Psicólogo; 2007.

9. Brasil. Secretaria da Educação Fundamental. Parâmetros Curriculares Nacionais: terceiro e quarto ciclos do ensino fundamental: introdução aos Parâmetros Curriculares Nacionais. Brasília: MEC/SEF, 1998.

10. Silva Junior AP, Dantas LS, Medeiros AG, Bahia CSA. Jogos escolares da rede pública de Ilhéus-Bahia: uma análise documental. Goiânia. 2016;19(3):557-567.

11. Melo GF, Rubio K. Mulheres atletas olímpicas brasileiras: início e final de carreira por modalidade esportiva. Rev. bras. ciênc. mov. 2017;25(4):5-12.

12. Brasil. Política nacional de educação física e desportos: Plano nacional de educação física e desportos - PNED. Brasília: MEC; 1976.

13. MEC. Avaliação dos X Jogos Escolares Brasileiros 1979. Brasília: Secretaria de Educação Física e Desportos; 1981a.

14. MEC. Avaliação dos XI Jogos Escolares Brasileiros 1981. Brasília: Secretaria de Educação Física e Desporto; 1981 b.

15. MEC. Avaliação dos III CEB’s. Desportos Coletivos 1982. Brasília: Secretaria de Educação Física e Desportos; 1982.

16. MEC. Avaliação dos XII Jogos Escolares Brasileiros 1983. Brasília: Secretaria de Educação Física e Desportos; 1983.

17. Dados fornecidos a nós via e-mail pelo COB em 2012.

18. Dados fornecidos a nós via e-mail pelo COB em 2017.

\author{
ENDEREÇO \\ André Almeida Cunha Arantes \\ Departamento de Educação Física \\ Centro Universitário de Brasília. \\ SEPN 707/907 - Asa Norte \\ 70790-075 - Brasília - Distrito Federal - Brasil \\ E-mail: andre.arantes@ceub.edu.br
}

Recebido para publicação: 16/12/2015

Revisado: 21/12/2017

Aceito: 01/02/2018 